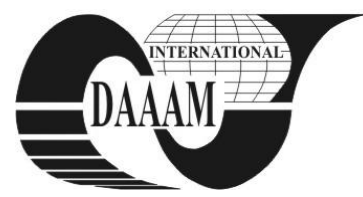

Annals of DAAAM for 2011 \& Proceedings of the 22nd International DAAAM Symposium, Volume 22, No. 1, ISSN 1726-9679 ISBN 978-3-901509-83-4, Editor B. Katalinic, Published by DAAAM International, Vienna, Austria, EU, 2011 Make Harmony between Technology and Nature, and Your Mind will Fly Free as a Bird Annals \& Proceedings of DAAAM International 2011

\title{
STRUCTURAL ANALYSIS OF CONCRETE SPHERICAL SHELLS
}

\author{
MEKJAVIC, I[vana]
}

Abstract: Studying landmark shells of the past can help engineers in designing efficient thin shell concrete structures. This paper presents structural analyses and the optimization study of several notable concrete spherical shells around the world. In structural optimization of these shells an attempt is made to reduce overall tensile stress, deflection and reinforcement to the system while changing the limits of the structure's shape. The finite element analysis using Sofistik software shows that a distributed concrete thickness reduces shell stresses, deflections and reinforcements.

Key words: concrete shells, spherical shells, structural analysis, structural optimization

\section{INTRODUCTION}

The widespread use of large-scale computer programs for structural analysis has reduced reliance on classical methods, providing insight into previously unsolved problems and hoping for automatic optimized design (Burger \& Billington, 2006; Draper et al., 2008; Holzer et al., 2008; Tomas \& Marti, 2010).

Using the Sofistik 2010 finite element program that solves large-scale structural analysis problems several spherical shell structures were examined. Fig. 1 shows some of the remarkable early shells of the Kresge - MIT Auditorium in Boston, Ehime Public Hall in Matsuyama and Het Evoluon in Eindhoven.

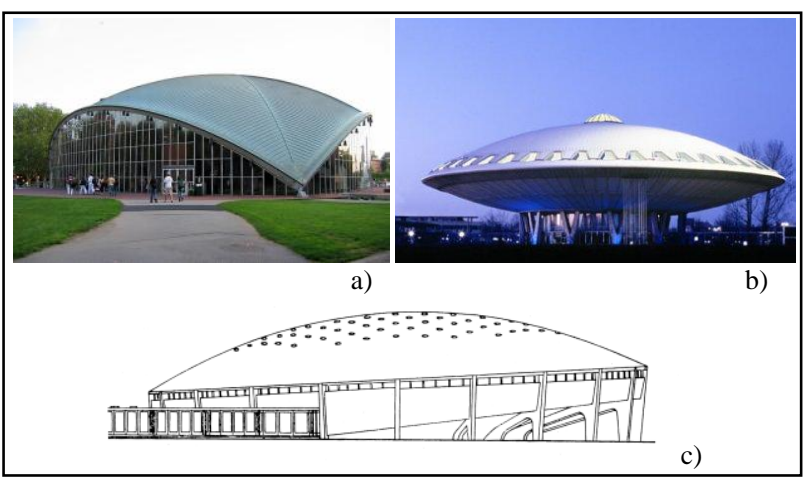

Fig. 1. Analyzed spherical shells, a) Kresge - MIT Auditorium in Boston, USA, b) Het Evoluon in Eindhoven, Netherlands, c) Ehime Public Hall in Matsuyama, Japan

Kresge - MIT Auditorium, designed by a noted modernist architect, Eero Saarinen, consists of a one-eighth spherical segment dome-shaped concrete roof, supported on three points with a $49 \mathrm{~m}$ span and $8,9 \mathrm{~cm}$ thickness increased near the edge beams up to $14 \mathrm{~cm}$. Additions had to be made to this structure, since Saarinen's sculptural cutting of the shell created severe edge disturbances to the membrane stresses in the shell that had to be counteracted by an edge beam $45,7 \mathrm{~cm}$ high. In the end, after the formwork was removed it was discovered that the edges were deflecting unacceptably (clearly well over $12,7 \mathrm{~cm}$ ) due to uncontrolled creep. Additional supports were added in the form of steel tubes which were also used to support the window wall (Ford, 2003).

The Ehime Public Hall in Matsuyama, Japan, designed by Japanese engineers, Tange and Tsuboi, is a shallow spherical inclined shell supported by 20 columns. A ring is provided around the base between columns. The thickness of the shell is $8 \mathrm{~cm}$ with a diameter of $49,35 \mathrm{~m}$ and a rise of $7 \mathrm{~m}$ at the crown.

The Het Evoluon in Eindhoven was the last major project of the Netherlands designer Louis Kalff. The building is unique due to its resemblance to a landed flying saucer, which makes it look very futuristic. The $77 \mathrm{~m}$ diameter dome rests on $12 \mathrm{~V}$ shaped columns. The overall height of the building is $30 \mathrm{~m}$.

\section{STRUCTURAL OPTIMIZATION STUDY}

The optimization studies of these structures fall into three categories: (1) A thickness optimization study that compares a shell with uniform thickness to the one in which the thickness is optimally distributed over the area, (2) a size optimization study that examines the size of the edge beam, and (3) a material optimization study.

The concrete material properties assume a unit weight of 25 $\mathrm{kN} / \mathrm{m}^{3}$, a Young's Modulus of $36 \mathrm{GPa}(\mathrm{C} 45 / 55)$ and a Poisson's ratio of 0,2 . The reinforcing steel material properties assume a yield strength of $500 \mathrm{MPa}$ and a Young's Modulus of $200 \mathrm{GPa}$. The load on the structure is its self weight and snow load of $1,25 \mathrm{kN} / \mathrm{m}^{2}$ uniformly distributed on the horizontal projection.

\subsection{Thickness optimization}

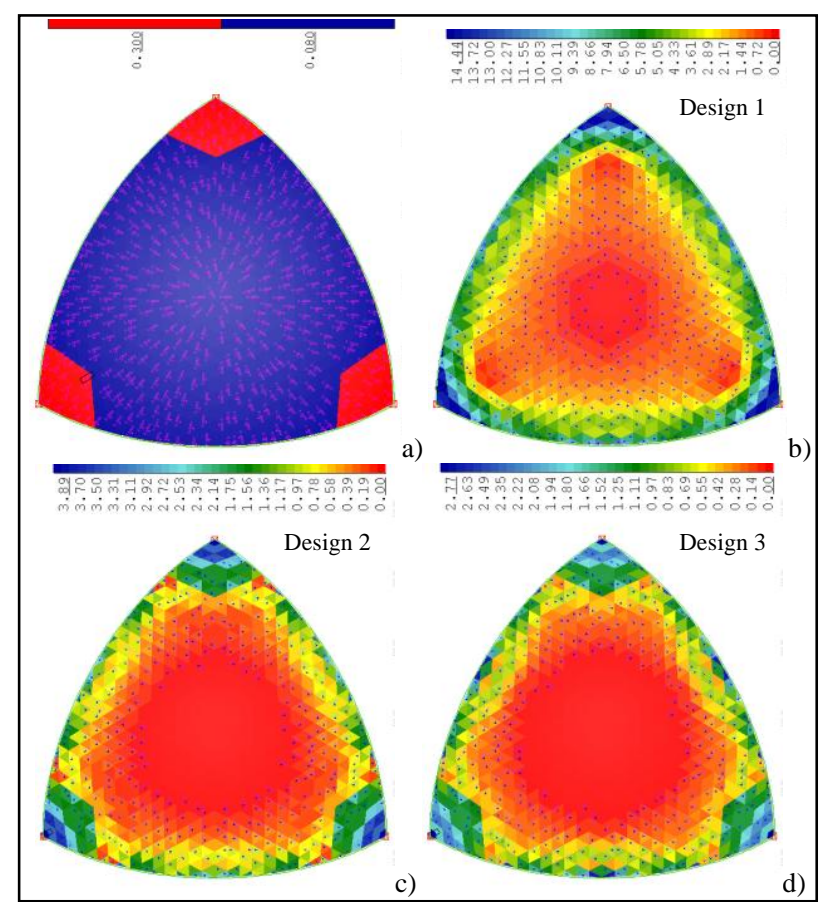

Fig. 2. Kresge shell a) structural optimization design, b)-d) principal tensile stresses (for dead load) 
The distribution of thickness was obtained via free optimization, that is, without a computer algorithm. The criterion for thickness optimization was the punching design performed by Bemess program in Sofistik. The optimum solution of the design task shows a clear distribution of larger thickness around the supports equal to $30 \mathrm{~cm}$ (Fig. 2a).

The deflections and maximum tensile stresses of the shell with an optimized thickness distribution (design 2) are compared to the same shell with edge beam of uniformly varying cross section (design 3) and another shell with a uniform thickness of $8,9 \mathrm{~cm}$ (design 1). In the original design 1 the concrete shell is reinforced with a stiffening beam $(20 \times 45$ $\mathrm{cm}$ ) around the perimeter of the building, and the concrete class is C30/37. In the design 2 the concrete strength of the shell with optimal thickness distribution and $20 \times 45 \mathrm{~cm}$ edge beam is C40/50. The design 3 comprises shell with optimal thickness distribution and $(30 \times 30 \mathrm{~cm}$ to $30 \times 70 \mathrm{~cm})$ edge beam with higher concrete strength $\mathrm{C} 45 / 55$. The maximum tensile stresses occur in the region of the supports, gradually decreasing to zero at the center of the shell. Figs $2 \mathrm{~b}-\mathrm{d}$ show the areas of maximum principal tensile stresses for the three shell designs. The design 3 develops less tensile area and smaller maximum tensile stresses, and thus is a more efficient design. In addition, it is seen that the deflections for the shells with the optimized thickness distribution (design 2 and 3) are much smaller than the shell with uniform thickness (design 1).

\subsection{Size and material optimization}

The effects of the beam size and material properties for the Kresge shell were also obtained via free optimization. The design variables that are changed are the height of the edge beam, and the concrete strength. The edge beam of uniformly varying cross section in design 3 enhances the shell stiffness, reducing maximum (principal) tensile stresses and deflection, and thereby reducing reinforcements (Tab. 1). Also, the higher concrete strength of $\mathrm{C} 45 / 55$ reduces the deflection and the amount of reinforcements.

\begin{tabular}{|l|l|l|}
\hline Design & $\begin{array}{l}\text { Top reinforcement } \\
\left(\mathrm{cm}^{2} / \mathrm{m}\right)\end{array}$ & $\begin{array}{l}\text { Bottom reinforcement } \\
\left(\mathrm{cm}^{2} / \mathrm{m}\right)\end{array}$ \\
\hline 1 & 32,87 & 39,58 Punching failure \\
\hline 2 & 20,56 & 49,75 \\
\hline 3 & 7,33 & 13,37 \\
\hline
\end{tabular}

Tab. 1. Reinforcements for three designs of Kresge shell

Structural optimization of Evoluon results in a shell with uniform thickness of $8 \mathrm{~cm}$, reinforced with meridional and hoop ribs. The principal tensile stresses are shown in Fig. 3.

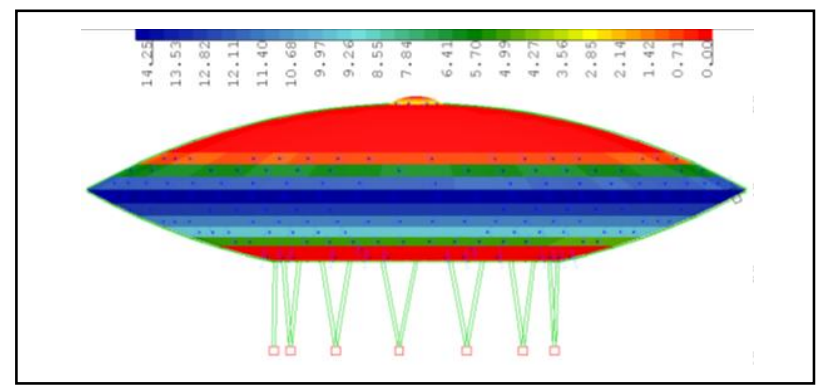

Fig. 3. Principal tensile stresses in Evoluon (for dead load)

\subsection{Shape optimization}

The effects of the shell rise are also obtained via free optimization. The values for diameter (span) and thickness of Ehime shell are kept constant in the shape optimization designs. The dimensions of the ring and columns are assumed equal to $40 \times 60 \mathrm{~cm}$ and $50 \times 50 \mathrm{~cm}$, respectively. The slope of the shell is set equal to $2^{\circ}$. The only variable that is changed is rise $d$. The rise $\mathrm{d}$ varies from 7,8 and 9 meters in this study. The effects of $\mathrm{d}$ on the maximum (principal) tensile stress, downward displacement and reinforcement for a spherical shell with a uniform thickness of $8 \mathrm{~cm}$ are examined. It is seen that the maximum principal tensile stress, downward deflection and reinforcement decrease with $\mathrm{d}$. Increasing the rise by cca $30 \%$ decreases the maximum principal tensile stresses, the deflections and the reinforcements by $23 \%, 34 \%$ and $20 \%$, respectively. Fig. 4 shows the areas of maximum principal tensile stress in the Ehime dome. It can be seen that bending moments and principal tensile stresses are restricted to a narrow zone at the edge of the dome. This area becomes smaller as the ring size increases.

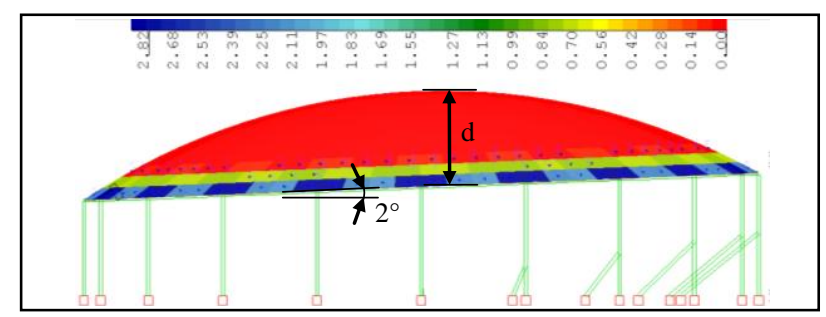

Fig. 4. Areas of tension in the Ehime dome (for dead load)

\section{CONCLUSION}

The finite element analysis in this paper demonstrates that structural optimization leads to a more efficient design of the analyzed concrete spherical shells and that such a tool is useful for designing thin shell concrete structures.

A detailed structural optimization study shows that a distributed thickness of the Kresge shell with the largest thickness at the supports leads to the most effective design in terms of reduced tensile stresses, reduced deflections, and most efficient use of material. It can be concluded that a distributed thickness is appropriate for this design. The results also indicate that the Kresge shell could have been designed with the edge beam of varying cross section and higher concrete strength than the documented $\mathrm{C} 30 / 37$ strength in order to reduce the excessive deflections. Structural optimization results of Evoluon indicate that the shell could have been designed as a ribbed model that would be less thick to reduce the weight. The shape optimization study of Ehime shell shows that the shell rise could have been larger than $7 \mathrm{~m}$ original design (flatter shell).

Future research should be conducted using the most sophisticated structural optimization techniques available today.

\section{REFERENCES}

Burger, N. \& Billington, D. P. (2006). Felix Candela, Elegance and Endurance: An Examination of the Xochimilco Shell, Journal of the International Association for Shell and Spatial Structures (IASS), Vol. 47, No. 3, pp. 271-278, ISSN 1996-9015

Draper, P.; Garlock, M. E. E. \& Billington, D. P. (2008). Optimization of concrete hyperbolic paraboloid umbrella shells, Available from: http://www.scribd.com/doc/51245877/Alex-ScordelisMemorial-Session, Accessed on: 2011-07-01

Ford, E. R. (2003). The Details of Modern Architecture, Vol. 2: 1928 to 1988, The MIT Press, ISBN 978-0-262-56202-7, Cambridge, Massachusetts

Holzer, C. E.; Garlock, M. E. E. \& Prevost, J. H. (2008). Structural Optimization of Felix Candela's Chapel Lomas de Cuernavaca, Available from: http://www.princeton.edu/ dynaflow/vitae/PageConference s.htm, Accessed on: 2011-07-05

Tomas, A. \& Marti, P. (2010). Shape and size optimization of concrete shells, Engineering Structures, Vol. 32, No. 6, pp. 1650-1658, ISSN 0141-0296 